\title{
ELECCIONES EN SCHLESWIG-HOLSTEIN Y BAJA SAJONIA
}

El 21 de marzo se celebraron las elecciones al Parlamento del Land Niedersachsen (Baja Sajonia) en la República Federal Alemana, convocatoria electoral que ha venido a confirmar las tendencias apuntadas en las anteriores elecciones comunales celebradas en Schleswig-Holstein (véanse cuadros 1 y 2). La importancia de estos comicios rebasa ampliamente el relativamente estrecho marco geográfico de ambos Lander. $Y$ ello no únicamente por lo que puedan significar en cuanto indicativos de las próximas elecciones federales a celebrar en 1984.

En muy pocas otras ocasiones habrá estado posiblemente tan vinculada la crisis de un partido determinado a una profunda crisis social. Desde el punto de vista meramente político estas elecciones evidencian una modificación importante del espectro político alemán. Los resultados definitivos arrojan dos datos fundamentales: por una parte, el aumento experimentado por los cristianodemócratas, dirigidos en la Baja Sajonia por Albrecht, que reafirma la mayoría absoluta (50,7 por 100) obtenida en las últimas elecciones comunales, frente al espectacular descenso de los socialdemócratas, quienes en cuatro años han perdido cerca de 200.000 votantes; por otra parte, la confirmación de que en el espectro político alemán hay que contar a partir de ahora con una nueva fuerza política, la representada por los ecologistas o «verdes» (Grünen), que han conseguido sobrepasar incluso a los liberales (6,5 por 100 frente a 5,9 por 100 de la FDP). Según los análisis realizados por el Instituto Infas de Bonn, los socialdemócratas perdieron 55.000 votos a favor de los liberales y casi otros 50.000 votantes se decidieron esta vez por los ecologistas. Considerando el estado actual de la opinión pública en Alemania, la vuelta de los liberales al Parlamento de la Baja Sajonia se debe en gran medida a su prudente distanciamiento de la SPD. Aunque ambos partidos forman todavía la coalición social-liberal en Bonn, los liberales, siguiendo el curso marcado por Genscher, ministro de Asuntos Exteriores y presidente de la FPD, han sabido mantener si no una opción ideológica nítidamente propia, sí al menos un alejamiento de la crisis interna que ha conmovido los más sólidos fundamentos de la SPD y que amenaza con acabar con la era socialdemócrata iniciada en 1969 tras la llegada al poder de Willy Brandt.

Las discusiones en el seno de la socialdemocracia alemana se deben básicamente a tres factores: el desgaste generacional de las viejas figuras - Herbert Wehner, Willy Brandt, Helmut Schmidt- que hicieron posible el mantenimiento de la 
SPD durante trece años en el poder y que no anhelan precisamente la inevitable hora del relevo; en segundo lugar, la radicalización de la lucha ideológica dentro del partido, manifestada en un intento de mayor ideologización por parte de la izquierda frente al tecnocratismo personalizador del poder que se le achaca a Helmut Schmidt; por último, el elemento que ha servido de espoleta para distanciar decisivamente a ambos sectores dentro del partido, y que no es otro que la crisis de la idea del progreso, una pérdida del utopismo técnico-industrial inherente a la SPD como «partido del futuro», que ha hecho mella en amplias capas sociales de la población germano-occidental. El debate público protagonizado en los últimos meses por destacadas figuras intelectuales de la socialdemocracia alemana en torno a la aceptación o rechazo de los nuevos valores - pacifismo, neutralización ideológica, ecologismo, vuelta a formas preindustriales de organización social y económica-, defendidos por amplios sectores de la juventud alemana, responde a una profunda pérdida de identidad del partido en el poder. De este modo, las últimas elecciones celebradas en la República Federal dejan entrever, junto a un más que posible cambio político en Bonn, una progresiva radicalización de las posturas ideológicas.

\section{Cuadro 1}

\section{ELECCIONES EN LA BAJA SAJONIA}

\begin{tabular}{|c|c|c|c|c|}
\hline & $\begin{array}{l}\text { Elecciones al } \\
\text { «Landtag» de } \\
4-6-1978\end{array}$ & $\begin{array}{c}\text { Elecciones al } \\
\text { Parlamento } \\
\text { Federal } \\
\text { («Bundestag») } \\
\text { de } 5-10-1980\end{array}$ & $\begin{array}{l}\text { Elecciones } \\
\text { comunales de } \\
27-9-1981\end{array}$ & $\begin{array}{l}\text { Elecciones al } \\
\text { «Landtag» de } \\
21-3-1982\end{array}$ \\
\hline Censo electoral $\ldots \ldots \ldots$ & 5.241 .051 & 5.363 .576 & 15.370 .693 & 5.402 .529 \\
\hline Participación electoral $\ldots . .$. & $78,5 \%$ & $89,3 \%$ & $76,2 \%$ & $77,9 \%$ \\
\hline Votos válidos $\ldots \ldots \ldots \ldots \ldots$ & 4.088 .183 & 4.755 .142 & 11.702 .037 & 4.178 .460 \\
\hline CDU (cristianodemócratas) ... & $\begin{array}{l}1.989 .326 \\
(48,7 \%)\end{array}$ & $\begin{array}{l}1.891 .813 \\
(39,8 \%)\end{array}$ & $\begin{array}{l}5.873 .742 \\
(50,2 \%)\end{array}$ & $\begin{array}{c}2.118 .118 \\
(50,7 \%)\end{array}$ \\
\hline SPD (socialdemócratas) $\ldots \ldots$ & $\begin{array}{l}1.723 .638 \\
(42,2 \%)\end{array}$ & $\begin{array}{r}2.232 .531 \\
(46,9 \%)\end{array}$ & $\begin{array}{l}4.319 .540 \\
(36,9 \%)\end{array}$ & $\begin{array}{l}1.526 .331 \\
(36,5 \%)\end{array}$ \\
\hline $\begin{array}{llllll}\text { FDP }(\text { liberales) } & \ldots & \ldots & \ldots & \ldots\end{array}$ & $\begin{array}{c}171.514 \\
(4,2 \%)\end{array}$ & $\begin{array}{r}535.914 \\
(11,3 \%)\end{array}$ & $\begin{array}{l}750.218 \\
(6,4 \%)\end{array}$ & $\begin{array}{c}246.973 \\
(5,9 \%)\end{array}$ \\
\hline Grünen (ecologistas) $\ldots \ldots \ldots$ & $\begin{array}{c}157.733 \\
(3,9 \%)\end{array}$ & $\begin{array}{l}77.475 \\
(1,6 \%)\end{array}$ & $\begin{array}{c}420.051 \\
(3,6 \%)\end{array}$ & $\begin{array}{c}273.270 \\
(6,5 \%)\end{array}$ \\
\hline DKP (comunistas) $\ldots \ldots \ldots \ldots$ & $\begin{array}{l}12.700 \\
(0,3 \%)\end{array}$ & $\begin{array}{l}7.020 \\
(0,1 \%)\end{array}$ & $\begin{array}{c}47.475 \\
(0,4 \%)\end{array}$ & $\begin{array}{c}11.591 \\
(0,3 \%)\end{array}$ \\
\hline NPD (nacionalistas) $\ldots \ldots \ldots$ & - & $\begin{array}{c}17.613 \\
(0,4 \%)\end{array}$ & $\begin{array}{c}7.107 \\
(0,1 \%)\end{array}$ & $\begin{array}{c}10.939 \\
(0,1 \%)\end{array}$ \\
\hline
\end{tabular}




\section{Cuadro 2}

\section{ELECCIONES EN SCHLESWIG-HOLSTEIN}

\begin{tabular}{|c|c|c|c|c|c|c|}
\hline \multirow{2}{*}{ PARTIDOS } & \multicolumn{2}{|c|}{ Elecciones comunales 1978} & \multirow{2}{*}{$\begin{array}{c}\text { Elecciones } \\
1 \text { "Lantadg" } \\
1979\end{array}$} & \multirow{2}{*}{$\begin{array}{c}\text { Elecciones } \\
\text { Federales } \\
1980\end{array}$} & \multicolumn{2}{|c|}{ Elecciones comunales 1982} \\
\hline & & Porcentaje & & & & Porcentaje \\
\hline CDU & 705.989 & 49,2 & 48,3 & 38,9 & 704.120 & 50,1 \\
\hline $\begin{array}{lllll}\text { SPD } & \ldots & \ldots & \ldots & \ldots\end{array}$ & 581.409 & 40,5 & 41,7 & 46,7 & 485.472 & 34,6 \\
\hline $\begin{array}{llllll}\text { FDP } & \ldots & \ldots & \ldots & \ldots\end{array}$ & 104.464 & 7,3 & 5,8 & 12,7 & 96.133 & 6,8 \\
\hline $\begin{array}{l}\text { SSW (minoría da- } \\
\text { nesa) ... ... } \ldots \\
\text { GLSH (ecologistas }\end{array}$ & 24.380 & 1,7 & 1,4 & - & 25.594 & 1,8 \\
\hline $\begin{array}{c}\text { Schlewig-H.) } \quad \ldots \\
\text {. }\end{array}$ & 10.113 & 0,7 & 2,4 & 1,4 & 12.089 & 0,9 \\
\hline Grünen $\ldots \ldots \ldots$ & - & - & - & - & 42.973 & 3,1 \\
\hline $\begin{array}{llllll}\mathrm{DKP} & \ldots & \ldots & \ldots & \ldots\end{array}$ & 7.433 & 0,5 & 0,2 & 0,1 & 3.816 & 0,3 \\
\hline
\end{tabular}

José María Beneyto 